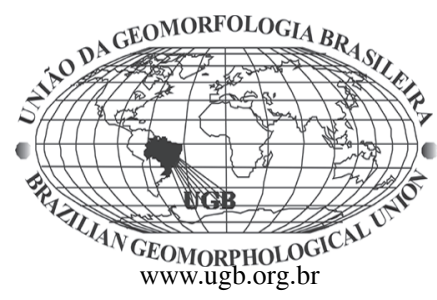

\title{
APICUNS: ASPECTOS GERAIS, EVOLUÇÃO RECENTE E MUDANÇAS CLIMÁTICAS GLOBAIS
}

\author{
Gisele Mara Hadlich \\ Universidade Federal da Bahia - Instituto de Geociências - Departamento de Geoquímica - UFBA/IGEO - \\ Av. Barão de Geremoabo, s/n. - Cep 40170-290 - Salvador - Bahia-e-mail: gisele@ufba.br
}

José Martin Ucha

Instituto Federal de Educação - Ciência e Tecnologia da Bahia - IF-BAHIA - Departamento de Ciências Aplicadas Rua Emídio dos Santos, s/n. - Cep 40301-015 - Salvador - Bahia-e-mail: ucha@ifba.edu.br

\begin{abstract}
Resumo
Os apicuns são áreas planas de elevada salinidade ou acidez, localizadas na região de supra-maré e desprovidas de vegetação ou com vegetação rasa; estão necessariamente associados a manguezais e são encontrados nas regiões intertropicais em todo o mundo. Na Baía de Todos os Santos - BTS os manguezais e apicuns ocupam, respectivamente, 177,6 km² e 10,2 km². A distribuição dos apicuns é irregular, não ocorrendo em todas as áreas de manguezais encontradas. A abertura de perfis nos apicuns evidenciou a presença de um pacote sedimentar de granulometria mais grosseira recobrindo sedimentos antigos de manguezais, de coloração escura e com presença de raízes em decomposição; níveis com conchas podem ser encontrados em profundidade. Pedologicamente trata-se de um perfil de solo enterrado. Na transição apicum-manguezal observa-se a presença de troncos mortos em superfície, comprovando o assoreamento local. A salinidade é elevada, comumente superior a 100. Nos locais onde as águas das chuvas e a drenagem removem o excesso de sais, ocorre o avanço da vegetação. Fotografias aéreas das últimas décadas mostram a estabilização de alguns apicuns, o recuo de outros devido ao avanço de manguezal e vice-versa, e a ocupação de apicuns pela carcinicultura ou supressão das bordas por aterros. Processos erosivos das encostas próximas, condições hidrológicas que envolvem o movimento das marés e o aporte de água doce (precipitação) determinam a evolução dos apicuns e sua relação com os manguezais e encostas adjacentes. Devido à sua localização e topografia, são apontados como ambientes que, diante de uma elevação do nível do mar, podem sofrer colonização por mangue, expandindo a área de manguezais em direção às terras secas (encostas próximas); são, portanto, considerados indicadores ambientais de mudanças climáticas globais. Entretanto, os estudos de evolução mostram que ocorrem tanto aumento quanto diminuição dos manguezais na BTS. Deve-se ter cuidado e realizar estudos espaciais amplos para que não sejam tiradas conclusões equivocadas, com base na evolução de apicuns, em relação a variações do nível do mar decorrentes do aquecimento global.
\end{abstract}

Palavras-chave: planície hipersalina, dinâmica ambiental, Baía de Todos os Santos.

\begin{abstract}
"Apicuns" are plain areas of high salinity or acidity, localized in the supra-tidal regions with no vegetation or shallow; they are necessarily associated to mangroves and can be found in inter-tropical zones worlwide. In Todos os Santos Bay - TSB, the mangroves and apicuns occupy, respectively, $177.6 \mathrm{~km}^{2}$ and $10.2 \mathrm{~km}^{2}$. The apicuns' distribution is irregular, not occurring in all areas of the mangroves. The excavation on the apicuns revealed the presence of a sedimentary pack of coarser granulometry recovering antique mangrove sediments dark colored and with the presence of roots in process of decomposition; some deeper levels with shells can be found. Pedologicaly that means a buried soil layer. In the apicun-mangrove transition it is observed the presence of dead branch on the surface, proving the local sediment overlapping. The salinity of the apicuns is hight, commonly exceeding 100. In the sites in which the rain water removes the excess of salts, the vegetation advance takes place. Aerial photographs of the last decades show the stabilization of some apicuns, the decline of others due to the advancement of
\end{abstract}


mangrove or vice versa, and the occupation of the apicuns by shrimp farms or removal of edges by landfills. Erosion processes of the nearby hills, hydrological conditions as the movement of the tides and the fresh water input (rain water) determine the evolution of the apicuns and its relation with the mangroves and adjacent hills. Due to its location and topography, the apicuns are described as ambiences that can be colonized by mangrove vegetation due to the elevation of the sea level. Therefore they are considered as environmental indicators of global climatic change. However, studies of the recent spacial evolution of the apicuns in the TSB show that occurs both increase an decrease in apicun's areas. Care should be taken and an ample space for spacial studies must be considered to eliminate wrong conclusions based on the evolution of apicuns in relation to changes in sea level resulting from global warming.

Keywords: hypersaline supratidal flats associated to mangroves, environmental dynamic, Todos os Santos Bay.

\section{Manguezais e apicuns}

Os manguezais são ecossistemas recentes sob aspecto geológico-geomorfológico, encontrados no litoral brasileiro entre Cabo Orange (AP) e Laguna (SC), ocupando uma área de cerca de $14 \mathrm{mil} \mathrm{km}^{2}$, o que configura o Brasil como segundo maior detentor de áreas de manguezais no mundo (SCHWAMBORN; SAINT-PAUL, 1996). Os manguezais são conhecidos pela sua relevância ecológica e também pela sua importância sócio-econômica devido às atividades de mariscagem desenvolvidas por comunidades próximas; participam da dinâmica geoambiental nos ambientes litorâneos cuja evolução depende dos fluxos de matéria e energia associados aos processos hidrodinâmicos derivados das oscilações de marés, vinculando trocas proporcionadas pela interação e interdependência entre os componentes do manguezal e de ecossistemas adjacentes. Nesse contexto situam-se os apicuns.

$\mathrm{O}$ apicum corresponde à área geralmente arenosa, ensolarada, e normalmente ocorre na porção mais interna do manguezal, na interface médio-supralitoral. Seu limite é estabelecido pelo nível médio das preamares equinociais (PROST, 2001). É desprovido de cobertura vegetal - apicum vivo (tanne vif, segundo Lebigre, 2007) - ou abriga vegetação herbácea, sendo, neste caso, designado apicum herbáceo (tanne herbacé).

Os apicuns são encontrados em áreas litorâneas intertropicais em todo o mundo, sempre associados a manguezais. Apicuns ocorrem em Madagascar, Senegal, Índia, Gabão, Austrália, Honduras, Papua-Nova-Guiné, Nicarágua, Equador, Nova Caledônia e México (MARIUS, 1985; DUKE, 2006; LEBIGRE, 2007). Esses ambientes são caracterizados pela elevada salinidade e estão relacionados à ocorrência de climas com regime de precipitação que comporta uma estação seca. Apesar de serem incluídos, pelo menos em parte, no contexto dos grandes conjuntos de ambientes hipersalinos (os sabkhas, depressões salinas em ambientes áridos), a obrigatoriedade de estarem associados a manguezais os difere de outros ambientes com elevada salinidade (LEBIGRE, 2007).
As referências relativas à origem dos apicuns no Brasil baseiam-se em estudos de Bigarella que, ao pesquisar o litoral paranaense na década de 40, afirma que, estando o manguezal em constante modificação, "durante as enchentes de preamar são depositados, sobre os manguezais, areias finíssimas [...]. Tais areias assim depositadas, tornam o banco de manguezal cada vez mais arenoso provocando a morte do mangue" (BIGARELLA, 2001, p. 74). Ucha et al. (2004), definindo apicuns como planícies arenosas hipersalinas, concordam com Bigarella ao afirmar que os apicuns são formas naturais de destruição do mangue, porém discordam no que se refere ao processo de origem. Afirmam que a formação dos apicuns deve-se à deposição de materiais siliciclásticos originários das adjacências que sofrem erosão, sendo a preamar responsável pela distribuição, seleção e transporte de argilas e silte para fora dos apicuns, restando o material arenoso no local. Essa deposição seria, assim, responsável pela morte do mangue original, o qual se torna incapaz de resistir às novas condições de elevada salinidade e aridez temporária.

Os apicuns raramente têm sido alvo específico de pesquisas nas áreas costeiras, e conhecimentos sobre eles estão geralmente associados a estudos de manguezais ou a mapeamento de zonas costeiras. Paralelamente, os apicuns constituem foco de discussões ambientais devido, principalmente, à implantação de atividades econômicas, sobretudo a carcinicultura.

Este artigo tem por objetivo trazer alguns elementos sobre a formação e evolução recente desses ambientes e, nesse quadro, verificar a possibilidade de utilizar estes ambientes como indicadores de variações do nível do mar, conforme tem sido apontado por diversos autores, seja para apicuns propriamente ditos, seja para ambientes semelhantes quando associados a manguezais (unvegetated saltflats, saltmarshes, supratidal flats etc) (SAINTILAN, WILLIAMS, 1999; ADAM, 2002; LEBIGRE, 1999; PORTUGAL, 2002; DUKE, 2006; DALE et al., 2007). Tomarse-á como referência apicuns encontrados na Baía de Todos os Santos, Bahia. 


\section{Distribuição Espacial de Apicuns e Manguezais na Baía de Todos os Santos - BTS}

Visando verificar a localização e distribuição de apicuns na BTS, foi realizado o mapeamento da área.

Para mapear os apicuns e os manguezais, na área delimitada pelas coordenadas 490.000-575.000mE e 8540.000$8612.000 \mathrm{mN}$, foram utilizadas imagens do satélite CBERS2/CCD (órbitas/pontos 148/114-115 de 18/07/05 e 149/114115 de 19/06/05). As imagens foram georreferenciadas e pro- cessadas (aumento de contraste, transformação IHS-RGB aumento de contraste da banda I - transformação IHS-RGB, segmentação limiar 10 e área 100 pixels, classificação supervisionada e edição vetorial) no ambiente Spring. Foram feitas campanhas em campo para validação do mapeamento.

O mapa final foi gerado em escala 1:100.000, "Apicuns e Manguezais - Baía de Todos os Santos, BA" (HADLICH e UCHA, 2008), adaptado na Figura 1, e mostra as áreas de manguezais e apicuns na BTS: $177,6 \mathrm{~km}^{2}$ e 10,2 km², respectivamente.

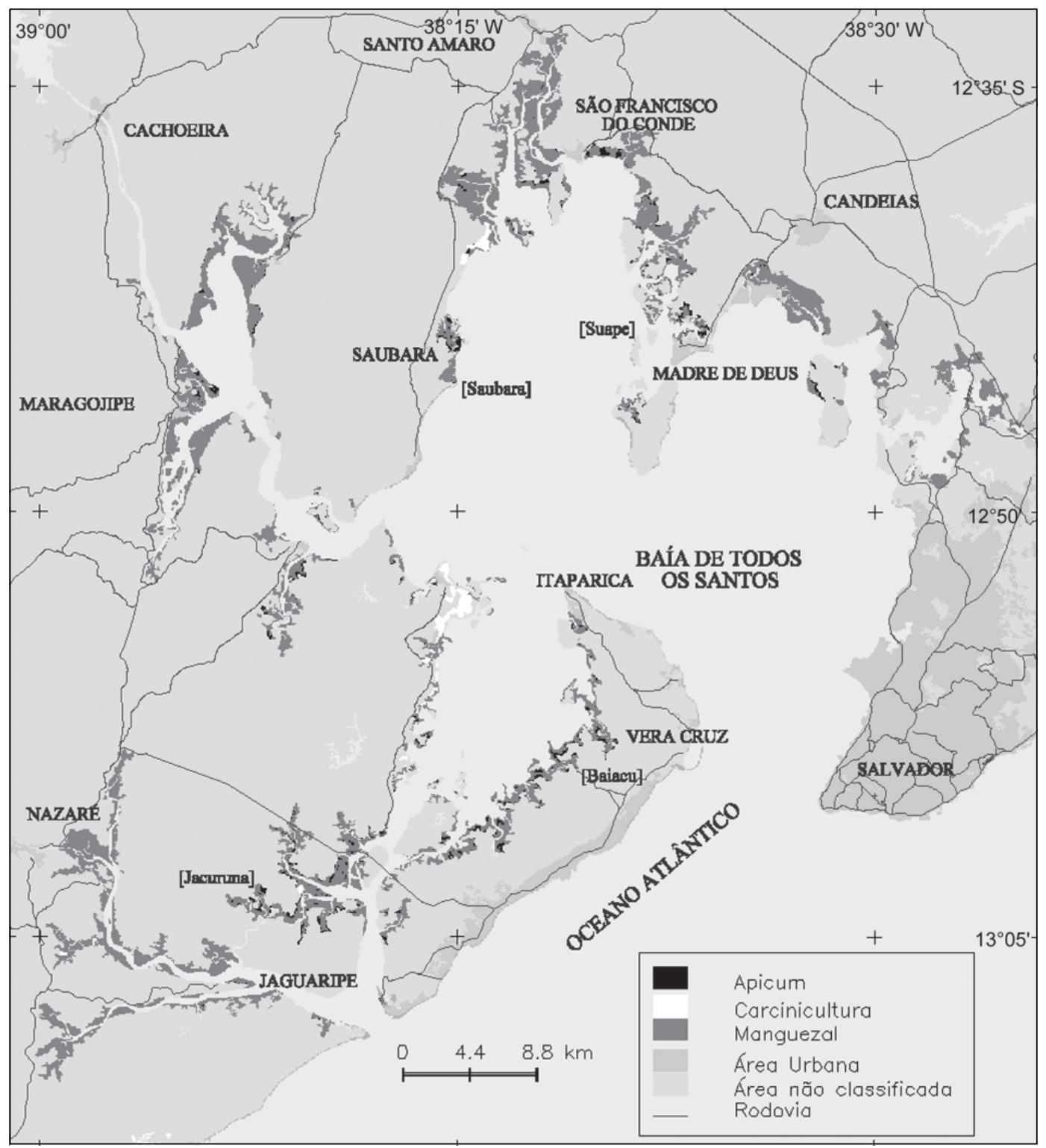

Figura 1 - Mapeamento de apicuns e manguezais na Baía de Todos os Santos, BA (original em escala 1:100.000) e indicação de localidades (estações) estudadas (entre colchetes). 
Apicuns desenvolvem-se geralmente em zonas marginais de manguezais, na interface médio-supra litoral, localizados entre manguezais e terras secas elevadas adjacentes, podendo ser encontrados no interior do bosque constituindo os chamados apicuns inclusos. Os apicuns mapeados na BTS confirmam essa tendência.

A Baía, com área de 1,1 mil km², possui um perímetro de aproximadamente $200 \mathrm{~km}$, sendo vastas áreas de suas margens ocupadas por manguezais. Quanto à localização dos apicuns, a quase totalidade encontra-se nas bordas dos manguezais, localizados próximos às áreas secas das encostas; raros são os apicuns inclusos. Sua distribuição, entretanto, apresenta grandes variações espaciais. Enquanto os manguezais se distribuem em toda a BTS (à exceção da área urbana de Salvador e das áreas litorâneas abertas ao mar), os apicuns concentram-se nas áreas SW-W (faixa ocidental da Ilha de Itaparica e próximo aos rios Jacuruna e Santana, em Jaguaripe) e, em menor quantidade, na Baía de Iguape, em Saubara e ao Norte da BTS, em São Francisco do Conde e em Madre de Deus.

Através da elaboração de um Modelo Numérico de Terreno - MNT a partir de imagens SRTM (Shuttle Radar Topography Mission) no aplicativo Spring e de checagem em campo, foi possível observar que os apicuns desenvolvem-se em locais onde há baixa declividade das encostas situadas a montante (principalmente até 6\%). Nesses locais o nível máximo das marés não atinge encostas íngremes, o que possibilita o desenvolvimento de faixas intermediárias entre terras secas e manguezais: os apicuns.

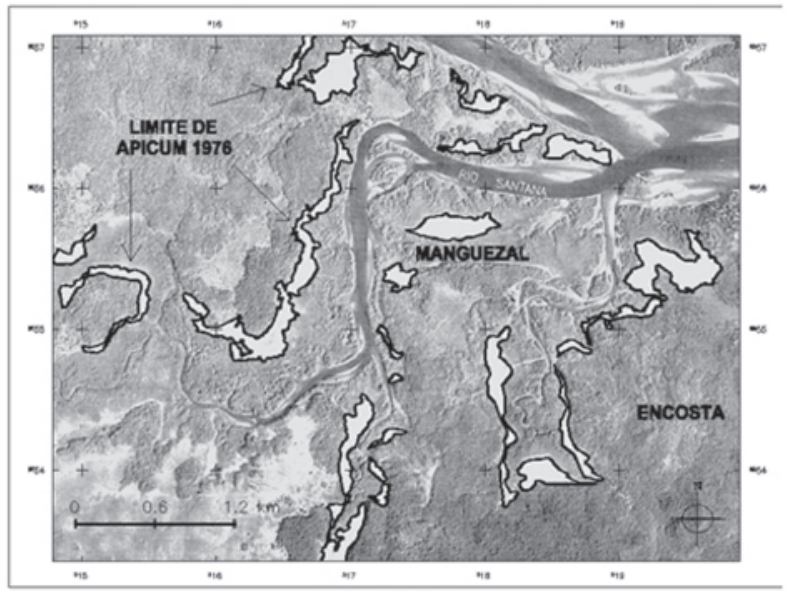

(a) 1976

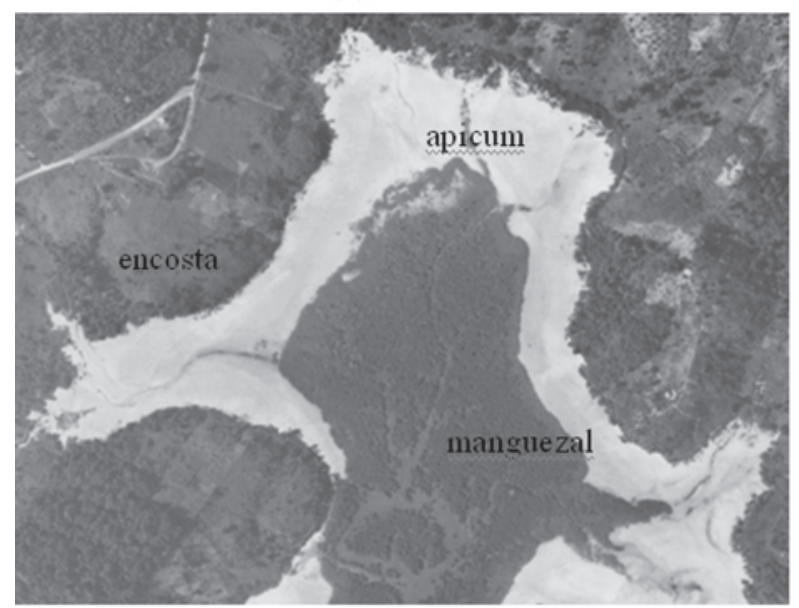

(c) 1989

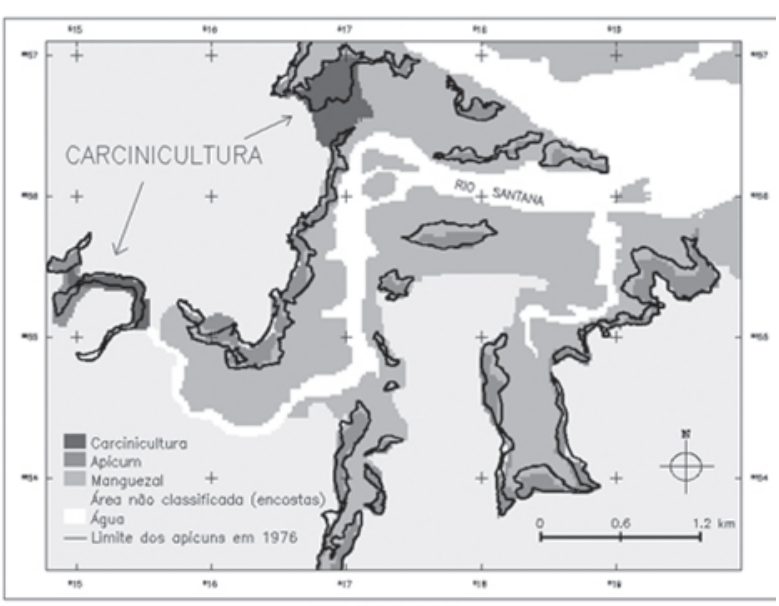

(b) 2007

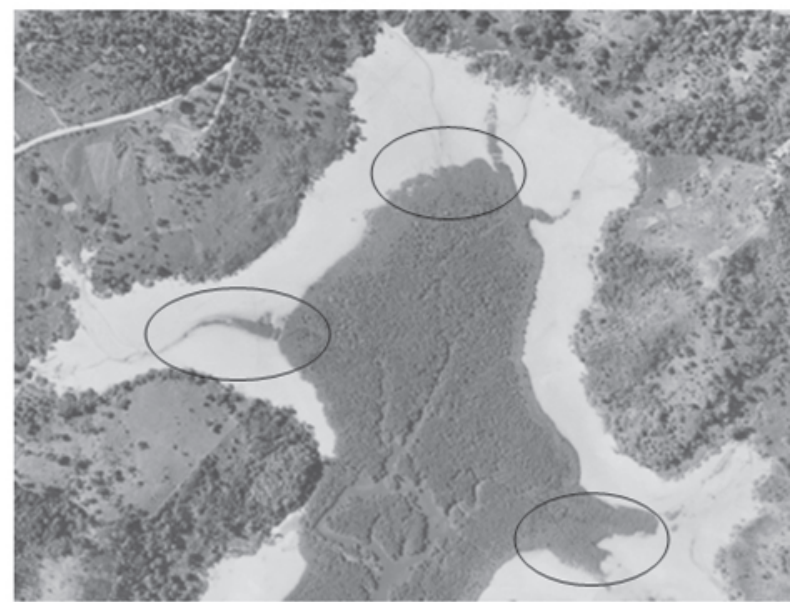

(d) 2001

Figura 2 - Aspectos da evolução dos apicuns: (a) fotografia aérea de 1976 (escala 1:40.000) e (b) mapa de 2007 (HADLICH e UCHA, 2008), em Jaguaripe; observa-se implantação de carcinicultura em algumas áreas de apicum e avanço do manguezal ou das encostas sobre o apicum. As figuras (c) (fotografia aérea de 1989) e (d) (foto de 2001), em Madre de Deus, mostram avanço de manguezal nas áreas de drenagem superficial. 


\section{Evolução Espacial Recente dos Apicuns}

Para avaliação da evolução recente de algumas áreas com apicuns, tomou-se como base fotografias aéreas de diferentes datas e/ou o mapa gerado (com base nas imagens de satélite de 2005), sendo feita uma comparação visual detalhada com auxílio do aplicativo Spring.

Análises locais evidenciam diferentes situações. Em diversas áreas, há estabilização das áreas de apicuns. Ocorre, também, sua redução devido à colonização por vegetação de mangue (Figura 2a,b). Apesar de em sua origem geológicogeomorfológica o apicum implicar em degradação do manguezal, este pode ser colonizado por espécies de mangue, conforme relatado por diversos autores (SCHAEFFERNOVELLI, 1999; LEBIGRE, 2007; OLIVEIRA et al., 2000; OLIVEIRA, 2005; MARIUS, 1985; SAINTILAN e WILLIAMS, 1999). Elevada pluviometria favorece a lixiviação dos sais nos apicuns, sobretudo em materiais mais arenosos, diminuindo a salinidade local e permitindo a instalação do mangue, uma vez que a elevada salinidade é apontada como principal fator limitante para o desenvolvimento da vegetação. Segundo INMET (2007), na região estudada houve aumento da precipitação média anual nos últimos 30

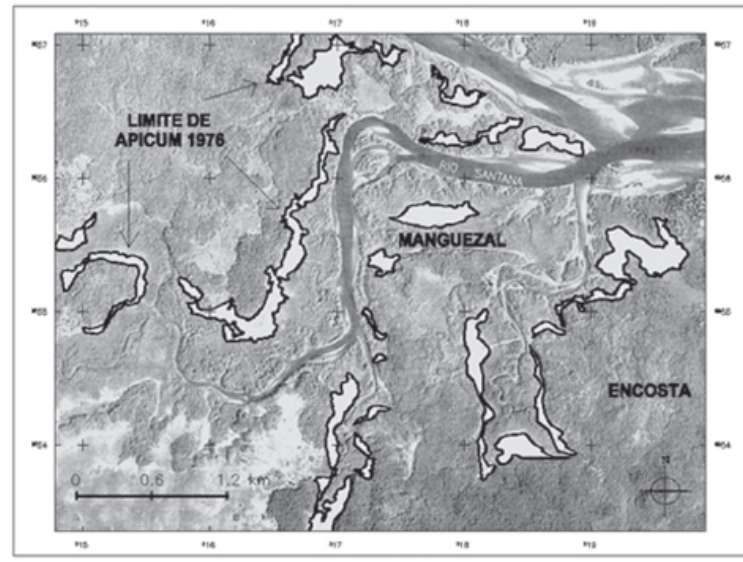

(a) 1976

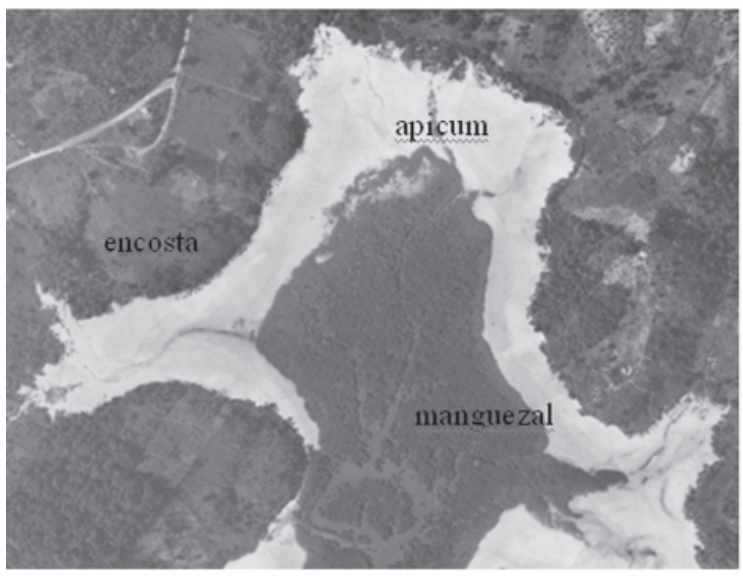

(c) 1989 anos quando comparada aos 30 anos anteriores, fator que propicia o avanço de manguezal sobre os apicuns.

Foi evidenciado, também, que áreas de apicuns foram ocupadas pela carcinicultura (Figura 2c,d), assim como ocorre em outras áreas do litoral nordestino (CREPANI e MEDEIROS, 2003; CAVALCANTI et al., 2007; OLIVEIRA et al., 2000). Além disso, bordas de apicuns, na interface encosta-apicum, foram aterradas, diminuindo sua área original, o que ocorreu em Madre de Deus e em Saubara (JESUS, 2008).

Já em Jacuruna, município de Jaguaripe, constata-se a presença de muitos espécimes de mangue morto na transição apicum-manguezal (Figura 3), indicando o avanço do apicum sobre o manguezal, conforme pôde ser constatado em fotografias aéreas. Na comunidade de Baiacu, município de Vera Cruz, também houve ampliação dos apicuns. Em campo, em alguns apicuns, verifica-se a ocorrência de troncos e raízes mortos de manguezal, indicando que, em algum momento, houve degradação da vegetação. Já em outros, adentrando o manguezal, são vistos troncos semelhantes, mortos, o que sugere que, após um avanço da área de apicum sobre a de manguezal que levou à mortandade, há ocorrência de retorno do manguezal sobre os apicuns.

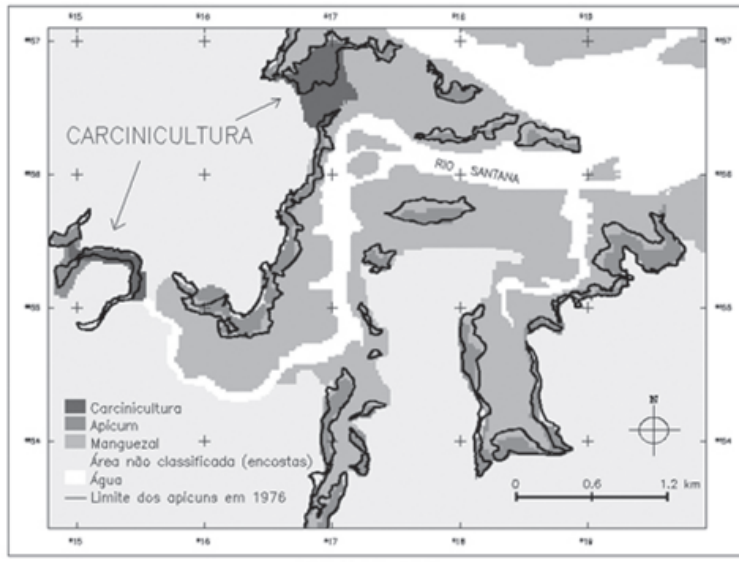

(b) 2007

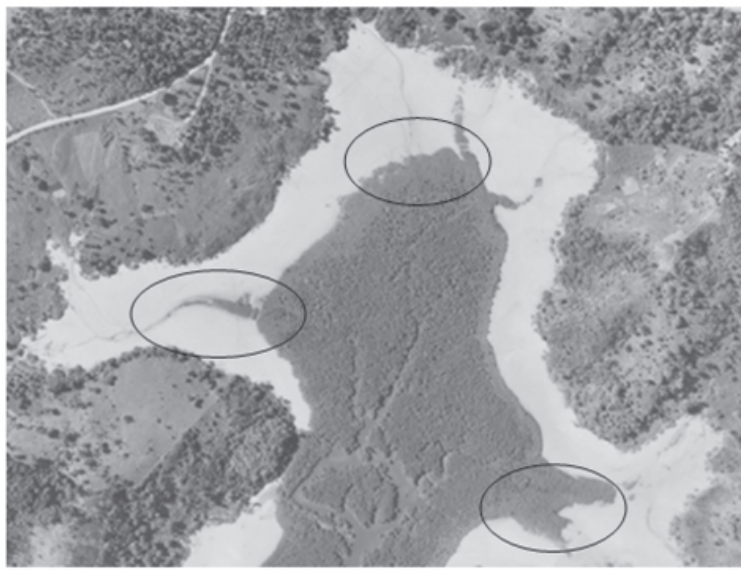

(d) 2001

Figura 3 - Troncos e raízes de mangue morto são encontrados na transição apicum-manguezal no município de Jaguaripe, indicando a progradação do apicum sobre o manguezal. Foto: 1302'01,86”S e 3850'54,56”W - WGS84, em 23 set. 2008. 


\section{Perfil Típico do Apicum}

Com base na distribuição dos apicuns e manguezais mapeados, foram selecionados quatro apicuns-piloto estudos mais detalhados, conforme mostrado na Figura 1.

Em campanha de campo (julho de 2007) foram realizados, em cada estação, o levantamento topográfico de uma topossequência atravessando o apicum (direção encostamanguezal) e a abertura de perfis ao longo desta, para sua descrição, até uma profundidade de aproximadamente 100$120 \mathrm{~cm}$.

As topossequências variaram, em comprimento, de 120 a 260 metros. Os apicuns apresentam relevo plano, com declividade em torno de $0,3 \%$ em direção ao manguezal.

Os perfis foram abertos com as seguintes localizações: ponto $\mathrm{A}$ - perfil no apicum próximo à encosta; ponto $\mathrm{B}$ - perfil no centro do apicum e ponto $\mathrm{C}$ - perfil no apicum, próximo ao manguezal. As profundidades escavadas nos perfis foram determinadas em função da presença do lençol freático ou da rocha subjacente. A caracterização dos perfis foi baseada no Sistema Brasileiro de Classificação de Solos (EMBRAPA, 1999).

O perfil típico encontrado nos apicuns é caracterizado por uma camada com aproximadamente $60 \mathrm{~cm}$ de profundidade formada por areia em superfície que pode passar a arenoargilosa em profundidade; há raízes mortas de mangue e/ou conchas de ostras entre 20 e $50 \mathrm{~cm}$, material este que se encontra assentado sobre os sedimentos autóctones (folhelhos argilosos do Grupo Ilhas em Madre de Deus, Baiacu e Saubara ou arenitos do Grupo Brotas em Jacuruna) ou sobre sedimentos de manguezal. A cor varia entre 10 YR 6/3 (bruno claro acinzentado) e 10 YR 3/1 (cinza muito escuro), com aparecimento de cores de redução (mosqueados) devido a flutuação do lençol freático em torno dos $50 \mathrm{~cm}$ de profundidade.

Pedologicamente trata-se de um perfil de solo enterrado, com perfeita identificação do antigo solum e visualização do soterramento posterior. O material orgânico soterrado (troncos, raízes e conchas) foi também encontrado por Ucha et al. (2004) na localidade de Mucujó, em Jaguaripe e no município de Valença, BA, por Nascimento (1999) em apicuns de Sergipe, e é descrito com as mesmas características por Marius (1987) no Senegal.

\section{Apicuns: uma combinação entre erosão, marés e pre- cipitações}

Os perfis dos apicuns mostram que camadas de material arenoso recobrem um antigo leito sobre o qual se desenvolveram a vegetação de mangue e espécies de moluscos que, com o seu soterramento, sucumbiram às novas condições do ambiente. Dessa forma, o apicum caracteriza-se como área sucessional de degradação da vegetação, e não como de agradação.

Diferentes autores, entretanto, citam a recolonização de apicuns ou variações nas áreas ocupadas pela vegetação, fato também observado em algumas áreas na Baía de Todos os Santos. O comportamento da vegetação reflete as condições climáticas anuais, estando associado à maior ou menor salinidade encontrada no apicum decorrente, respectivamente, do menor ou maior aporte de água pluvial no ambiente. Variações anuais e a importância do clima na evolução dos apicuns são citadas por Marius (1985) e Lebigre (2003, 2007).

Paralelamente, observações em campo mostraram processos erosivos de encostas em períodos de precipitação intensa, com deposição do material fino a grosseiro nos apicuns. Verificou-se que, dias após a deposição, o material fino havia sido removido devido à ação das marés mais elevadas, dos escoamentos pluviais e do efeito dispersante do sódio, restando o material grosseiro. Esse material grosseiro, ao longo do tempo, eleva o nível topográfico do apicum, evidenciando assoreamento.

Esta dinâmica determina a ampliação ou o retrocesso das áreas de apicuns e adjacências: por um lado, a erosão provoca um avanço do material sedimentar oriundo das encostas sobre os apicuns ou mesmo dos apicuns sobre os manguezais, gerando modificações hidrológicas de superfície e subsuperfície e diferenciações nas condições de acúmulo de sais; por outro, as variações pluviométricas implicam em diferente aporte de água pluvial no sistema, capaz de promover (ou não) uma lavagem dos sais. Estes processos, associados, permitem ou restringem o avanço de diferentes espécies vegetais sobre os apicuns.

Toda a dinâmica do apicum e, por conseguinte, do manguezal próximo, depende das condições de salinidade que, por sua vez, estão relacionadas às condições climáticas e à oscilação das marés. Assim como verificado para saltmarshes (ADAM, 2002; DALE et al., 2008), alterações no nível relativo dos mares ou na amplitude das marés possuem repercussão sobre as áreas de apicuns, podendo sua evolução (ou involução) ser indicadora de mudanças ambientais locais ou globais.

Entretanto, outros fatores também são apontados como importantes na evolução dos apicuns, como alterações na circulação hídrica estuarina provocadas por construção de barragens, drenagens, dragagens do leito dos rios próximos aos manguezais e apicuns, ou subsidência de áreas devido à exploração de óleo e gás, ou ainda modificações locais devido à construção de estradas e aterros ou outros (DUKE, 2006; DALE et al., 2007; LEBIGRE, 2003; 2007).

O estudo realizado mostrou que, em uma mesma baía, localidades diversas podem apresentar comportamento evolutivo espacial dos apicuns diferenciado. Isto evidencia a 
importância de analisar vários apicuns em uma mesma região e expandir trabalhos, incluindo pesquisas de modificações hidrodinâmicas, de neotectônica ou subsidência de origem antrópica. Deve-se ter cuidado, portanto, ao analisar porções limitadas de apicuns e elegê-los como indicadores de modificações do nível médio do mar - assunto que atualmente mobiliza a comunidade científica mundial.

\section{Agradecimentos}

As pesquisas sobre apicuns realizadas na Baía de Todos os Santos foram executadas com apoio financeiro do Conselho Nacional de Desenvolvimento Científico e Tecnológico $\mathrm{CNPq}$, projeto "Mapeamento e caracterização de apicuns na Baía de Todos os Santos, BA". O mapeamento contou com o apoio do Engenheiro Fernando Yutaka Yamaguchi, IBGE Unidade Estadual da Bahia e do acadêmico Thiago Leal de Oliveira (Iniciação Científica/UFBA).

\section{Referências Bibliográficas}

ADAM, P. Saltmarshes in a time of change. Environmental Conservation, v. 29, n. 1, p.39-61. 2002.

BIGARELLA, J. J. Contribuição ao estudo da planície litorânea do estado do Paraná. Brazilian Archives of Biology and Technology, Jubilée Volume 19462001), p. 65-110. 2001. (Artigo original: Boletim Geográfico, 1947, n. 55, p. 747-779).

CAVALCANTI, D. R.; CARVALHO, E. V. T.; ZAGAGLIA, C. R.; BARRETO, R.; SANTOS, R. N. de A. Detecção de viveiros de carcinicultura e de salinas com imagens CBERS-2 e Landsat, localizados na APA Delta do Parnaíba. In: SIMPÓSIO BRASILEIRO DE SENSORIAMENTO REMOTO, 13, 2007, Florianópolis. Anais... São José dos Campos: INPE, 2007. p. 3813-3819.

CREPANI, E.; MEDEIROS, J. S. de. Carcinicultura em apicum no litoral do Piauí: uma análise com sensoriamento remoto e geoprocessamento. In: SIMPÓSIO BRASILEIRO DE SENSORIAMENTO REMOTO, 11, 2003, Belo Horizonte. Anais... São José dos Campos: INPE, 2003. p. 1541-1548.

DALE, P.; KNIGHT, J.; BREITFUSS, M.; RADKE, L; ROGERS, K. Saltmarsh and saltflat areas. OzCoast - Information about Australia's estuaries and coasts. Disponível em: < http://www.ozcoasts.org.au/ indicators/changes_saltmarsh_area.jsp $>$ Acesso em: 14 dez. 2007.

DUKE, N. Australia's mangroves. The authoritative guide to australian's mangrove plants. University of Queensland, Brisbane, 2006. 200 p.
EMBRAPA. Sistema brasileiro de classificação de solos. Brasília: Embrapa/SPI, Rio de Janeiro: Embrapa Solos, 1999. $412 \mathrm{p}$.

HADLICH, G. M.; UCHA, J. M. Apicuns e manguezais Baía de Todos os Santos - 2007. Salvador: NEA/ IGEO/UFBA, 2008. Escala 1:100.000.

INMET - Instituto Nacional de Meteorologia. Balanço hídrico climático. Disponível em:<http:// www.inmet.gov.br/html/agro.html>. Acesso em: 12 out. 2007.

JESUS, R. S. Apicuns: evolução recente e importância social em Madre de Deus e em Saubara, Bahia. 2008. Monografia (Graduação em Geografia) - Instituto de Geociências, Universidade Federal da Bahia, Salvador, 2008.

LEBIGRE, J-M. Les marais à mangroves de NouvelleCalédonie: un exemple de milieu 'naturel' lagonaire. Nouvelle Calédonie: Centre de Documentation Pédagogique, 2003. 42 p. (Dossier).

LEBIGRE, J-M. Les marais à mangrove et lês tannes. Disponível em: http://www.futura-sciences.com/fr/ print/comprendre/dossiers/doc/t/geographie/d/lesmarais-a-mangrove-et-les-tannes_683/c3/221/p1/ . Acesso em: 01 nov. 2007.

MARIUS, C. Mangroves du Senegal et de la Gambie: ecologie - pédologie - géochimie, mise en valeur et aménagement. Paris: ORSTOM, 1985. (Collection Travaux et Documents, 193).

NASCIMENTO, S. A. Estudo da importância do "apicum" para o ecossistema manguezal. Aracaju: ADEMA, 1999. 34p.

OLIVEIRA, A.; BESSA, C. N.; MOREIRA, I. C. de N. Aquicultura estuarina no Estado do Maranhão. In: INTERNATIONALCONFERENCEMANGROVE 2000, Recife. Anais... Recife. CD-ROM.

OLIVEIRA, V. F. de. Influência do estresse hídrico e salino na germinação de propágulos de Avicennia schaueriana Stapf e Leechman ex Moldenke e Laguncularia racemosa (L.) Gaertn. f. 2005. Dissertação (Mestrado em Botânica) - Instituto de Pesquisas Jardim Botânico do Rio de Janeiro, Escola Nacional de Botânica Tropical, Rio de Janeiro, 2005.

PORTUGAL, A. M. M. Manguezais de Guaratiba frente à perspectiva de elevação do nível médio relativo do mar, Baía de Sepetiba, Estado do Rio de Janeiro - Brasil. 2002. Dissertação (Mestrado em Ciências) - Instituto Oceanográfico, Universidade de São Paulo, São Paulo, 2002. 
PROST, M. T. (coord.). Projeto Manguezais paraenses: recursos naturais, usos sociais e indicadores para a sustentabilidade. Relatório Final. Belém: MCT/Museu Paranaense Emilio Goeldi, SECTAM, 2001. CD-ROM. (Programa de Estudos Costeiros, PEC)

SAINTILAN, N.; WILLIAMS, R. J. Mangrove transgression into saltmarsh environmets in south-east Australia. Global Ecology and Biogeography, v. 8, p. 117124. 1999.

SCHAEFFER-NOVELLI, Y. Grupo de ecossistemas: manguezal, marisma e apicum. São Paulo, 119 p. Programa Nacional da Diversidade Biológica Pronabio. Projeto de Conservação e Utilização Sustentável da Diversidade Biológica Brasileira Probio. Subprojeto Avaliação e Ações Prioritárias para a Conservação da Biodiversidade da Zona
Costeira e Marinha. 1998. Disponível em: <http:/ /www.bdt.fat.org.br/workshop/costa/mangue/>. Acesso em: 03 abr. 2006.

SCHWAMBORN, R.; SAINT-PAUL, U. Mangrove forgotten forests? Natural Resources and Development, v. 43/44, p. 13-36, 1996.

SUGUIO, K.; MARTIN, L.; BITTENCOURT, A. C. S. P. Flutuações do nível do mar durante o Quaternário superior ao longo do litoral brasileiro e suas implicações na sedimentação costeira. Rev. Bras. Geociências, v. 15, n. 4, p. 273-286. 1985.

UCHA, J. M.; SANTANA, P. S.; GOMES, A. S. R.; BARRETO, E. DO N.; VILAS-BOAS, G. DA S.; RIBEIRO, L. P. Apicum: gênese nos campos arenosos e degradação dos manguezais em dois municípios baianos. E.T.C. - Educação, Tecnologia e Cultura, v. 3, n. 2, p. 26-27. 2004. 